\title{
Band-Notched Ultrawide Band Planar Inverted-F Antenna
}

\author{
H. T. Chattha, ${ }^{1}$ M. K. Ishfaq, ${ }^{2}$ Y. Saleem, ${ }^{3}$ Y. Huang, ${ }^{4}$ and S. J. Boyes ${ }^{4}$ \\ ${ }^{1}$ Department of Electrical Engineering, University of Engineering and Technology Lahore, Faisalabad Campus, Faisalabad, Pakistan \\ ${ }^{2}$ Department of Electrical Engineering, GC University, Faisalabad, Pakistan \\ ${ }^{3}$ Department of Computer Science and Engineering, University of Engineering and Technology Lahore, Pakistan \\ ${ }^{4}$ Department of Electrical Engineering and Electronics, University of Liverpool, Liverpool L69 3GJ, UK
}

Correspondence should be addressed to H. T. Chattha, chattha43@hotmail.com

Received 25 February 2012; Accepted 9 April 2012

Academic Editor: Minh-Chau Huynh

Copyright (C) 2012 H. T. Chattha et al. This is an open access article distributed under the Creative Commons Attribution License, which permits unrestricted use, distribution, and reproduction in any medium, provided the original work is properly cited.

\begin{abstract}
A novel ultrawide band planar inverted-F antenna with band-notched characteristics is presented in this paper. The planar inverted-F antenna uses two parasitic elements to enhance the bandwidth to cover the ultrawide band. The band-notched feature is added by inserting a W-shaped slot on the top radiating element of the antenna with a band rejection from 5.08 to $6 \mathrm{GHz}$ (measured). Both the measured and simulated results are obtained to draw the conclusions.
\end{abstract}

\section{Introduction}

A considerable amount of research has been conducted for developing the ultrawide band (UWB) antennas for its characteristics such as high data rate, being low power, and having wide bandwidths, and simple hardware structure in many real world applications. In 2002, Federal Communications Commission (FCC) of USA allocated a bandwidth from 3.1 GHz to $10.6 \mathrm{GHz}$ to ultrawide band [1]. This band also covers the bands of the previously present wireless networks with standards such as IEEE 802. 11a in USA $(5.15-5.35 \mathrm{GHz}$, 5.725-5.825 GHz), HIPERLAN/2 in Europe (5.15-5.35 GHz, 5.47-5.725 GHz), and Microwave Access (WiMAX) system $(5.25-5.825 \mathrm{GHz})[2,3]$. To avoid the interference between these UWB systems and the nearby communication systems such as wireless (WLAN), there is a need to employ some form of filter. In order to save the space and cost and reduce the complexity of the UWB system, this filter should ideally be integrated into the radiating element of the antenna. To tackle this issue, many printed type of antennas with band-notched characteristics have been presented [2-10]. All these antennas have almost omnidirectional radiation patterns; however, some UWB applications require antennas with comparatively higher directivity.
The planar inverted-F antenna (PIFA) is now widely used in mobile and portable radio applications due to its simple design, lightweight, low cost, conformal nature, reliable performance, and attractive radiation pattern [1114]. The PIFA has higher directivity as compared to the planar monopole antennas which makes it more suitable for certain UWB applications [15]. PIFA was previously known as an antenna having narrow-band characteristics and a reasonable research is already done to enhance its impedance bandwidth [16-18]. Feik et al. have shown in [19] that the fractional impedance bandwidth up to about $25 \%$ can be obtained by having different shapes of feed plates. Recently, some UWB PIFA antennas are introduced $[20,21]$ and one band-notched UWB PIFA is introduced using a spiral slot [22] on the feed plate. However, the UWB PIFAs presented in the $[21,22]$ have height $h=7.5 \mathrm{~mm}$ which is relatively high and also it has two PIFA antennas (one on each edge of the ground plane) to cover the whole UWB band which makes it very difficult to integrate with other PCB components. This paper presents a single-element band-notched UWB PIFA for height $h=4.5 \mathrm{~mm}$ by introducing a W-shaped slot on the top radiating plate. 


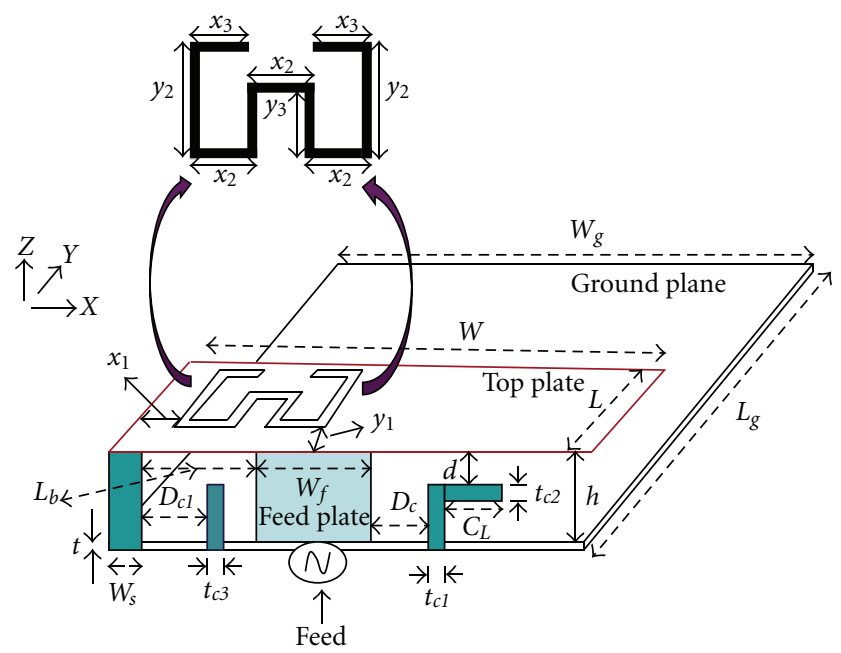

Figure 1: PIFA geometry.

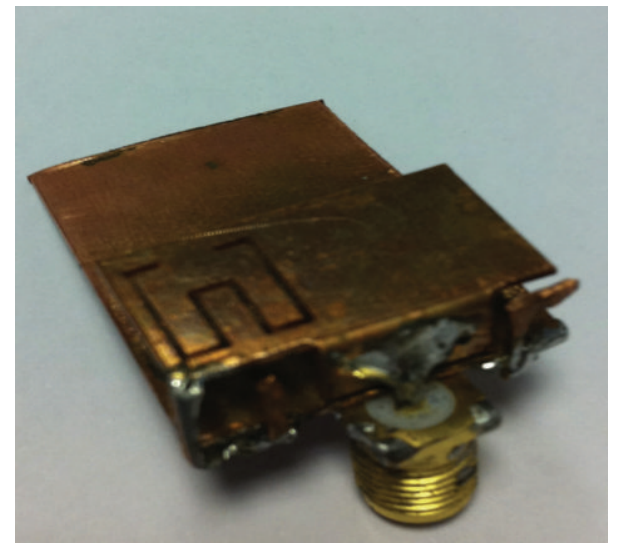

FIGURE 2: The built PIFA with SMA connector.

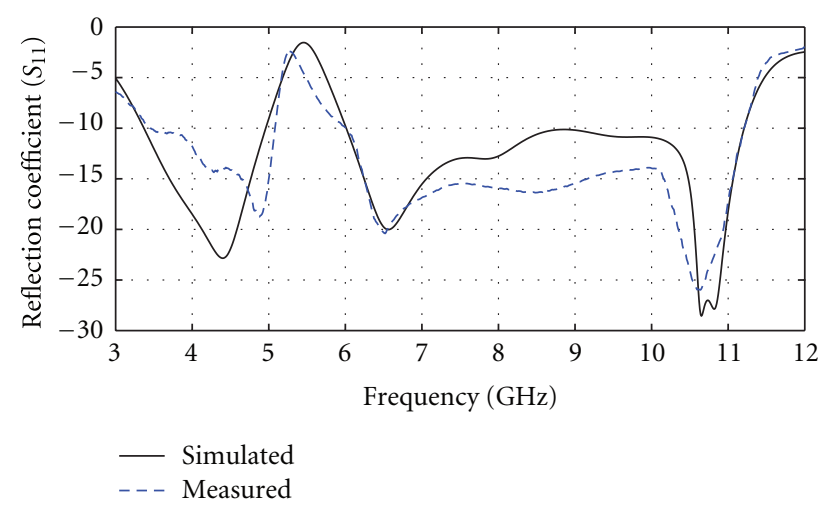

Figure 3: Ref. coefficients $S_{11}(\mathrm{~dB})$ versus frequency $(\mathrm{GHz})$.

\section{Antenna Configurations}

The structure of the designed PIFA as shown in Figure 1 has a radiating top plate with dimensions of width $W$ and length $L$ and $W_{g}$ and $L_{g}$ are width and length of the ground plane. The

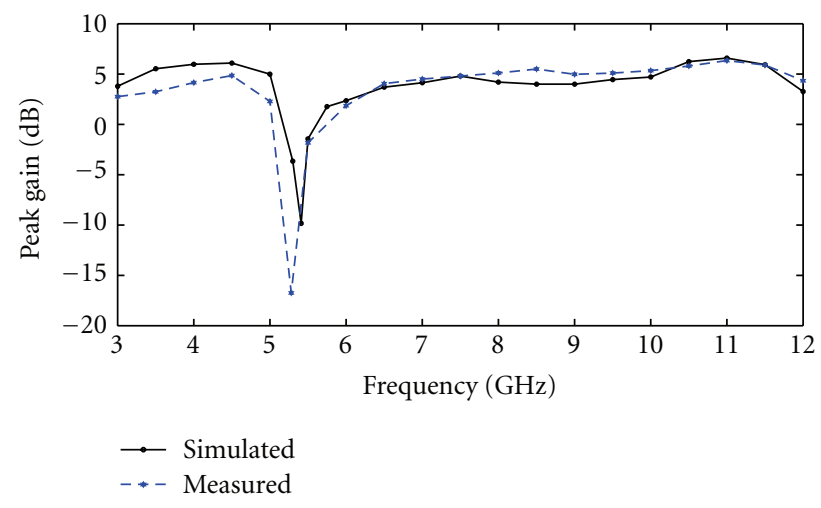

Figure 4: Simulated peak gain $(\mathrm{dB})$ versus frequency $(\mathrm{GHz})$.

dimensions of the shorting and feeding plates are $W_{s} \times(h+t)$ and $W_{f} \times h$, respectively, having a horizontal distance of $L_{b}$ between them and $h$ is the height of the antenna having air in the space between the top plate and the substrate. The distance of the parasitic element having a shape of an inverted-L from the feeding plate is $D_{c}$. This parasitic element has a thickness of $t_{c 1}$. The horizontal extension of this element is $C_{L}$ having a thickness of $t_{c 2}$. Second parasitic element rectangular in shape is inserted at the upper edge of the ground plane at a distance $D_{c 1}$ from the shorting plate. The width of this element is $t_{c 3}$. The heights of both the parasitic elements are the same and is equal to $(h+t)-d$ having a vertical distance of $d$ between the elements and the radiating plate. The $\mathrm{W}$-shaped slot on the top plate is inserted at a distance $x_{1}$ from the side edge and at a distance of $y_{1}$ from the upper edge of the top plate. The W-shaped slot is shown separately in Figure 1 to highlight its dimensions. The thickness of the slot is $0.5 \mathrm{~mm}$. The feeding to the PIFA is provided by a coaxial cable with an SMA connector as shown in Figure 2. 


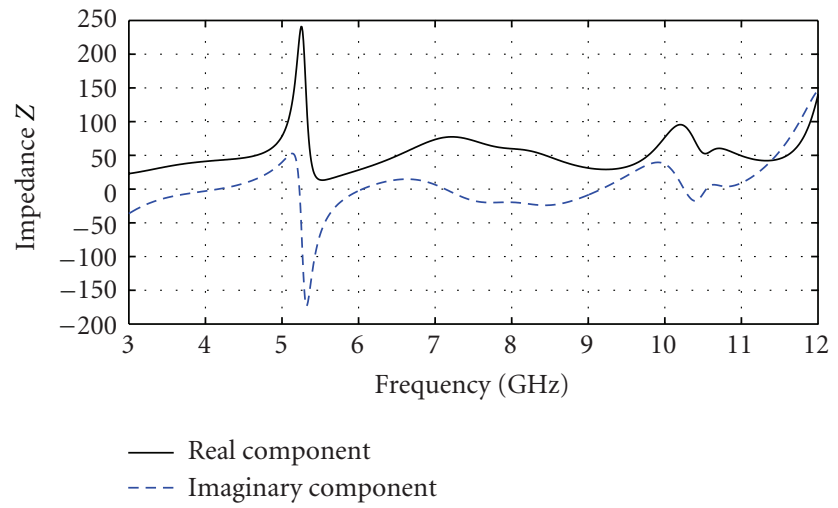

FIGURE 5: Impedances $Z(\Omega)$ versus frequency $(\mathrm{GHz})$.

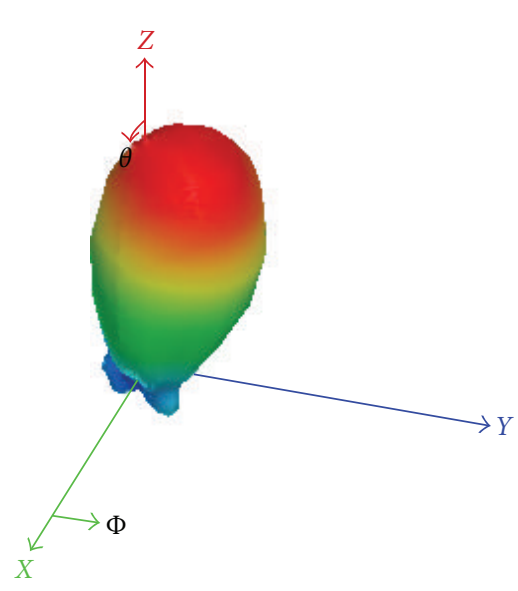

Gain total

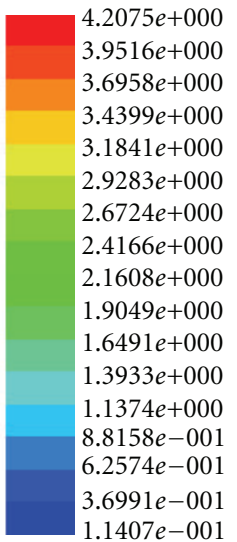

Figure 6: Simulated 3D radiation pattern of PIFA at 7.5 GHz.

\section{Results}

The optimization of the entire antenna parameters is performed through parametric study in high frequency structure simulator (HFSS) in order to get the maximum impedance bandwidth and feed is provided at the upper edge of the ground plane. The optimized values of all the parameters are found as follows: $W_{g}=18.5 \mathrm{~mm}, h=$ $4.5 \mathrm{~mm}, L_{g}=28 \mathrm{~mm}, W=18.5 \mathrm{~mm}, L=10 \mathrm{~mm}, W_{f}=$ $8.5 \mathrm{~mm}, W_{s}=0.5 \mathrm{~mm}, L_{b}=5.5 \mathrm{~mm}, D_{c}=0.5 \mathrm{~mm}, D_{c 1}=$ $0.07 \lambda=3 \mathrm{~mm}, t_{c 1}=t_{c 2}=t_{c 3}=0.5 \mathrm{~mm}, \mathrm{~d}=0.5 \mathrm{~mm}$, $(h+t)-d=5 \mathrm{~mm}, C_{L}=2.5 \mathrm{~mm}, x_{1}=1 \mathrm{~mm}, y_{1}=1 \mathrm{~mm}$, $x_{2}=2.5 \mathrm{~mm}, x_{3}=2 \mathrm{~mm}, y_{1}=1 \mathrm{~mm}, y_{2}=7.5 \mathrm{~mm}$, and $y_{3}=4.2 \mathrm{~mm}$.

The simulated and experimental results of the reflection coefficient are shown in Figure 3. It is evident that the bandwidth achieved by these techniques of inserting parasitic elements for $S_{11}<-10 \mathrm{~dB}$ is extremely broad from about 3.4 to $11.2 \mathrm{GHz}$. The lower frequency and first resonance is controlled by the main structure of PIFA, whereas the insertion of inverted-L-shaped parasitic element creates a second resonance at $6.5 \mathrm{GHz}$, and the presence of rectangularshaped parasitic element produces a third resonance around
10.7 GHz (simulated). Due to the insertion of W-shaped slot, band-notched characteristics are introduced with a band rejection from 5.08 to $6 \mathrm{GHz}$ (measured). The simulated and measured results are generally in good agreement. Their differences are mainly due to the cables and connectors which are not being involved in the simulations but exist in the measurements and the manufacturing tolerance in getting the accurate parameters in the manual fabrication of this antenna. Figure 4 shows the simulated and measured peak gain of the band-notched PIFA as a function of frequency in GHz. A sharp decrease in peak gain is observed in the notched frequency band centered at around $5.3 \mathrm{GHz}$ (measured) which confirms that this antenna provides a good level of rejection to signals at frequencies within the notched band. The impedance $Z$ of this PIFA versus the frequency in $\mathrm{GHz}$ is shown in Figure 5 to get a better understanding of this antenna.

The simulated 3D radiation pattern (polar plot) of the band-notched PIFA at $7.5 \mathrm{GHz}$ is shown in Figure 6 and the measured 2D radiation patterns of this antenna are shown in Figure 7. Figure 8 shows the simulated timedomain response of the PIFA to an input pulse which affirms the suitability of the PIFA for UWB applications. 


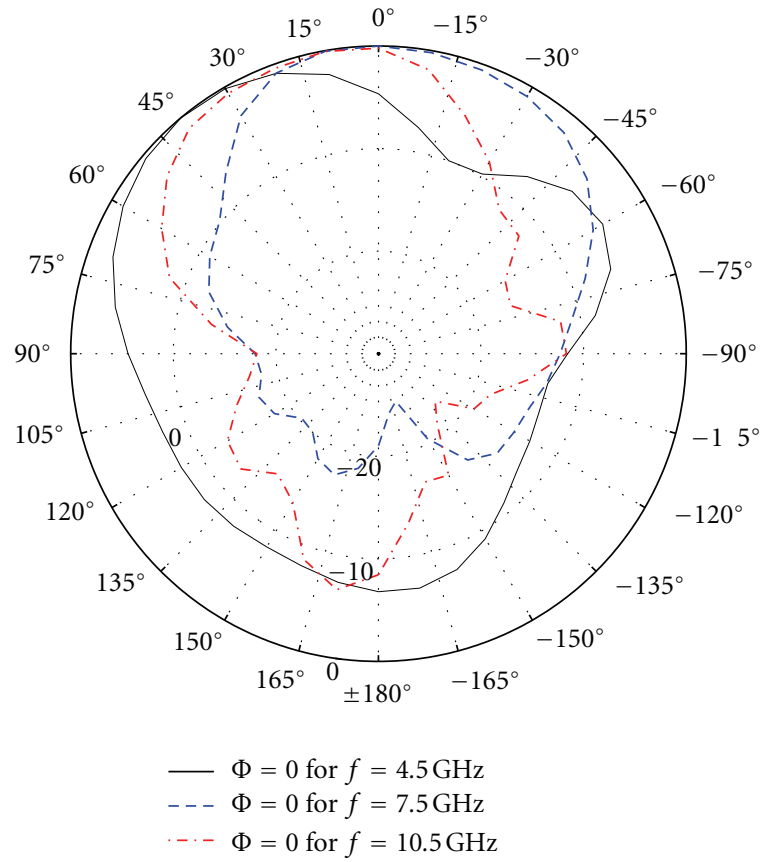

(a)

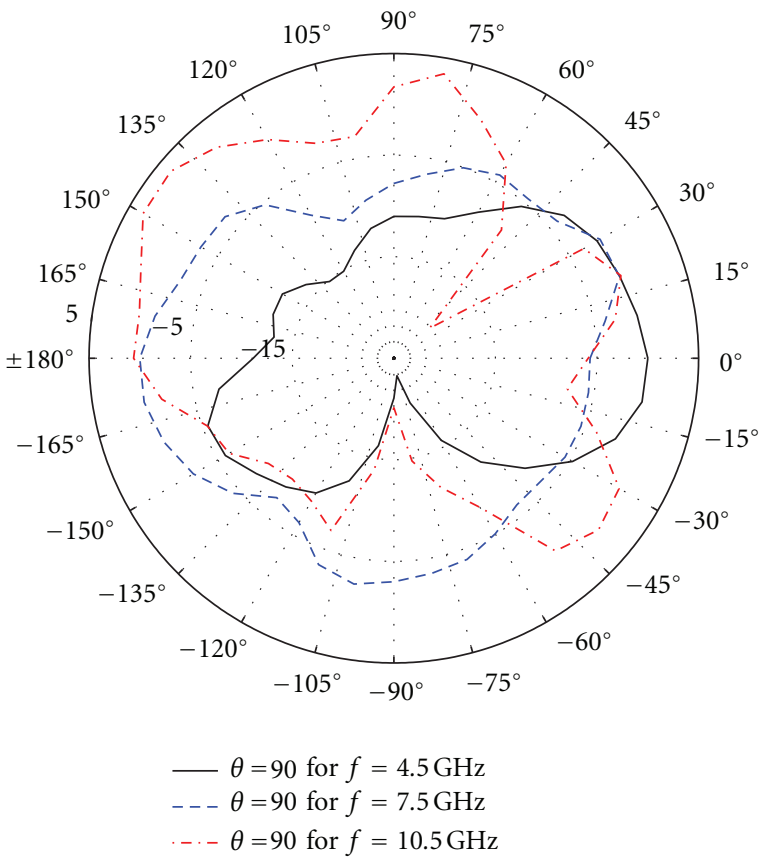

(b)

Figure 7: (a) 2D rad. pattern with total gain in $\mathrm{dB}$ for elevation $X Z$ plane $\left(\Phi=0^{\circ}\right)$ for diff. frequencies, (b) 2D rad. pattern with total gain in $\mathrm{dB}$ for azimuth $X Y$ plane $\left(\theta=90^{\circ}\right)$ for different frequencies.

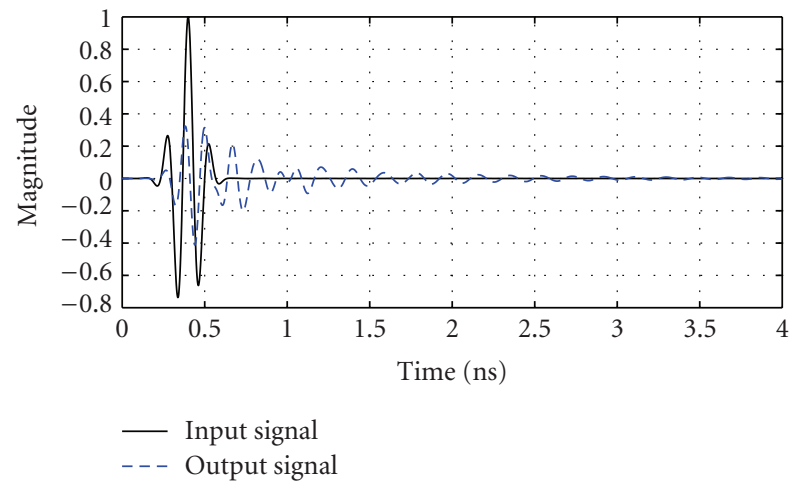

FIGURE 8: The time domain response of PIFA.

\section{Parametric Study}

The parameters of the $\mathrm{W}$-shaped slot are varied to observe its effects on the band-notched characteristics of the PIFA antenna. The distance $x_{1}$ from the side edge of the top plate is varied from $1 \mathrm{~mm}$ to $10 \mathrm{~mm}$ while all other parameters are held constant. Figure 9 shows the variation of $x_{1}$ versus the frequency in $\mathrm{GHz}$ which makes it obvious that position of the W-slot on the top plate does not significantly affects the notched band of the PIFA but significantly affects the performance of PIFA over the UWB band.

Similarly the length of the outer legs of the W-shaped slot $y_{2}$ is varied from $5 \mathrm{~mm}$ to $7 \mathrm{~mm}$ to observe its effects. Figure 10 shows that varying the length $y_{2}$ changes the band

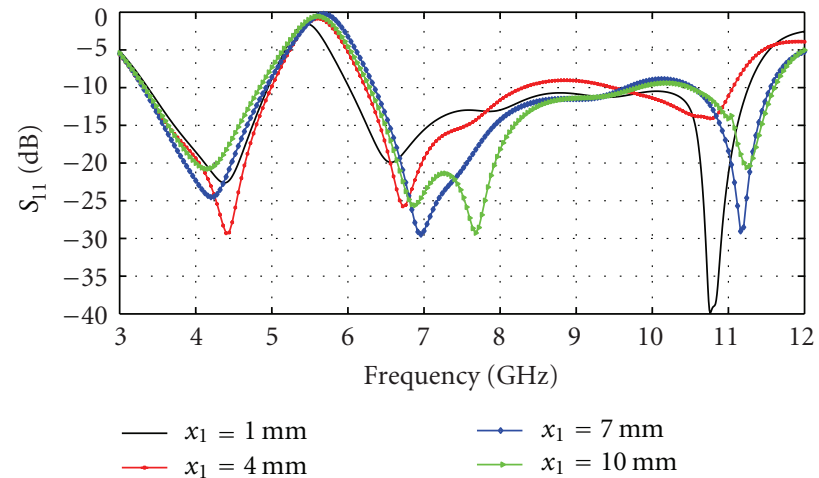

Figure 9: Simulated $S_{11}(\mathrm{~dB})$ for values of $x_{1}$ versus frequency (GHz).

which is notched by the insertion of $\mathrm{W}$-shaped slot whereas it does not significantly affect the performance of the PIFA over the UWB band. Therefore, we can vary the length $y_{2}$ to change the band to be notched. In the similar way, the length of the inner legs of the $\mathrm{W}$-shaped slot $y_{3}$ is also varied from $2 \mathrm{~mm}$ to $6 \mathrm{~mm}$ to observe its effects on the performance of the W-shaped slot and on the overall performance of the PIFA. It is obvious as shown in Figure 11 that the length $y_{3}$ is very critical parameter to decide which band is exactly to be notched. Varying the length $y_{3}$ also varies the performance of the PIFA over the UWB band. Therefore, an appropriate and optimized value of $y_{3}$ is required to get the exact band 


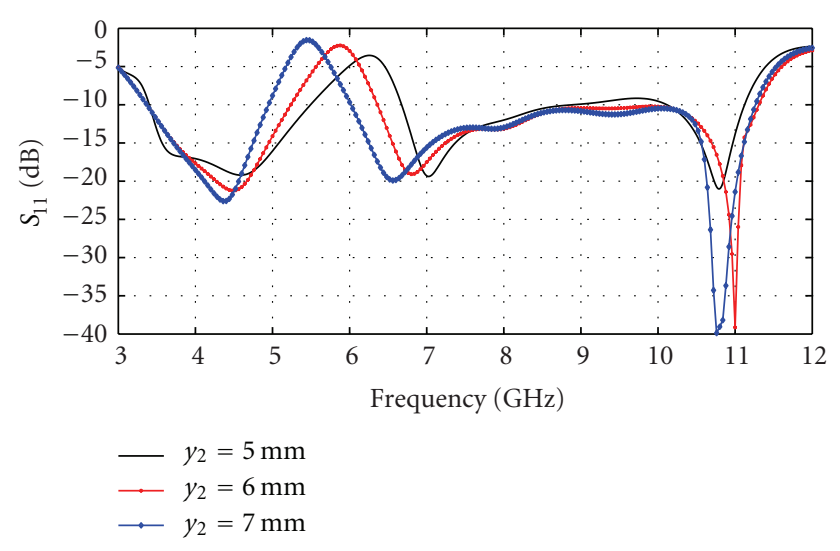

FIGURE 10: Simulated $S_{11}(\mathrm{~dB})$ for values of $y_{2}$ versus frequency (GHz).

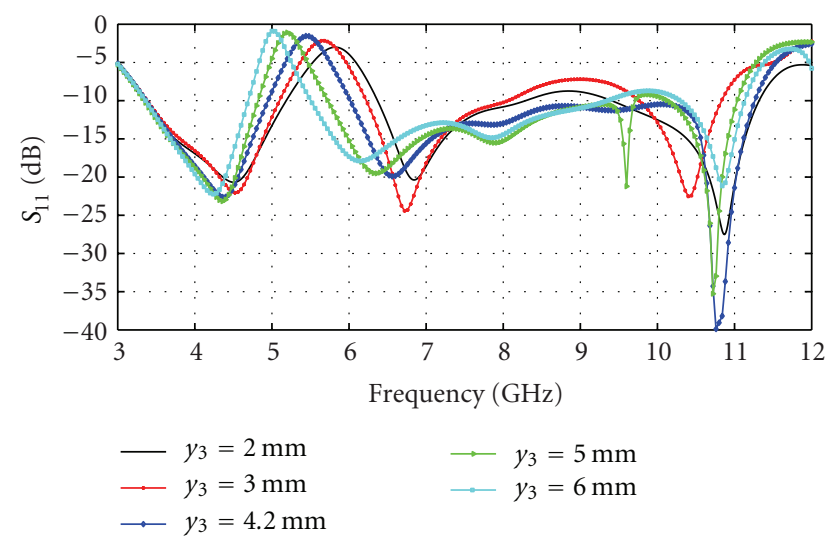

Figure 11: Simulated $S_{11}(\mathrm{~dB})$ for values of $y_{3}$ versus frequency $(\mathrm{GHz})$.

to be notched by the $\mathrm{W}$-shaped slot and also to achieve the reflection coefficient below $-10 \mathrm{~dB}$ over the UWB band.

\section{Conclusions}

A band-notched UWB PIFA antenna is presented in this paper. It has been shown that a very wide bandwidth is achieved which almost covers the whole UWB band from 3.4 to $11.2 \mathrm{GHz}$ and a band rejection from 5.08 to $6 \mathrm{GHz}$ is achieved by inserting a $\mathrm{W}$-shaped slot on the top plate.

\section{References}

[1] "FCC first report and order on ultra-wideband technology," February 2002.

[2] Y. D. Dong, W. Hong, Z. Q. Kuai et al., "Development of ultrawideband antenna with multiple band-notched characteristics using half mode substrate integrated waveguide cavity technology," IEEE Transactions on Antennas and Propagation, vol. 56, no. 9, pp. 2894-2902, 2008.

[3] Q. X. Chu and Y. Y. Yang, "A compact ultrawideband antenna with $3.4 / 5.5 \mathrm{GHz}$ dual band-notched characteristics," IEEE
Transactions on Antennas and Propagation, vol. 56, no. 12, pp. 3637-3644, 2008.

[4] J. R. Kelly, P. S. Hall, and P. Gardner, "Planar band-notched UWB antenna," in Proceedings of the 3rd European Conference on Antennas and Propagation (EuCAP '09), pp. 1636-1639, March 2009.

[5] Y. J. Cho, K. H. Kim, D. H. Choi, S. S. Lee, and S. O. Park, "A miniature UWB planar monopole antenna with 5-GHz bandrejection filter and the time-domain characteristics," IEEE Transactions on Antennas and Propagation, vol. 54, no. 5, pp. 1453-1460, 2006.

[6] A. J. Kerkhoff and H. Ling, "Design of a band-notched planar nonopole antenna using genetic algorithm optimization," IEEE Transactions on Antennas and Propagation, vol. 55, no. 3, pp. 604-610, 2007.

[7] S. J. Wu, C. H. Kang, K. H. Chen, and J. H. Tarng, "Study of an ultrawideband monopole antenna with a band-notched open-looped resonator," IEEE Transactions on Antennas and Propagation, vol. 58, no. 6, pp. 1890-1897, 2010.

[8] J. Qiu, Z. Du, J. Lu, and K. Gong, "A planar monopole antenna design with band-notched characteristic," IEEE Transactions on Antennas and Propagation, vol. 54, no. 1, pp. 288-292, 2006.

[9] W. S. Lee, W. G. Lim, and J. W. Yu, "Multiple band-notched planar monopole antenna for multiband wireless systems," IEEE Microwave and Wireless Components Letters, vol. 15, no. 9, pp. 576-578, 2005.

[10] S. W. Qu, J. L. Li, and Q. Xue, "A band-notched ultrawideband printed monopole antenna," IEEE Antennas and Wireless Propagation Letters, vol. 5, no. 1, pp. 495-498, 2006.

[11] K. Hirasawa and M. Haneishi, Analysis, Design, and Measurement of Small and Low-Profile Antennas, Artech House, 1992.

[12] K. L. Virga and Y. Rahmat-Samii, "Low-profile enhanced$\mathrm{B}$ and width PIFA antennas for wireless communications packaging," IEEE Transactions on Microwave Theory and Techniques, vol. 45, no. 10, pp. 1879-1888, 1997.

[13] P. S. Hall, E. Lee, and C. T. P. Song, "Planar invertedF antennas, chapter 7," in Printed Antennas for Wireless Communications, R. Waterhouse, Ed., John Wiley \& Sons, 2007.

[14] Y. Huang and K. Boyle, Antennas: from Theory to Practice, John Wiley \& Sons, 2008.

[15] H. T. Chattha, Y. Huang, M. K. Ishfaq, and S. J. Boyes, "A comprehensive parametric study of planar inverted-F antenna," Scientific Research Wireless Engineering and Technology, vol. 3, no. 1, pp. 1-11, 2012.

[16] D. Liu and B. Gaucher, The Inverted-F Antenna Height Effects on Bandwidth, IEEE, IBM T. J. Watson Research Centre, Yorktown Heights, NY, USA, 2005.

[17] F. Wang, Z. Du, Q. Wang, and K. Gong, "Enhanced-bandwidth PIFA with T-shaped ground plane," Electronics Letters, vol. 40, no. 23, pp. 1504-1505, 2004.

[18] P. W. Chan, H. Wong, and E. K. N. Yung, "Wideband planar inverted-F antenna with meandering shorting strip," Electronics Letters, vol. 44, no. 6, pp. 395-396, 2008.

[19] R. Feick, H. Carrasco, M. Olmos, and H. D. Hristov, "PIFA input bandwidth enhancement by changing feed plate silhouette," Electronics Letters, vol. 40, no. 15, pp. 921-923, 2004.

[20] H. T. Chattha, Y. Huang, Y. Lu, and X. Zhu, "An ultrawideband planar inverted-F antenna," Microwave and Optical Technology Letters, vol. 52, no. 10, pp. 2285-2288, 2010.

[21] C. H. See, R. A. Abd-Alhameed, D. Zhou, H. I. Hraga, P. S. Excell, and M. B. Child, "Ultra-wideband planar inverted FF antenna," Electronics Letters, vol. 46, no. 8, pp. 549-550, 2010. 
[22] H. I. Hraga, C. H. See, R. A. Abd-Alhameed et al., "PIFA antenna for UWB applications with WLAN band rejection using spiral slots," in Proceedings of the 5th European Conference on Antennas and Propagation (EUCAP '11), pp. 22262229, April 2011. 

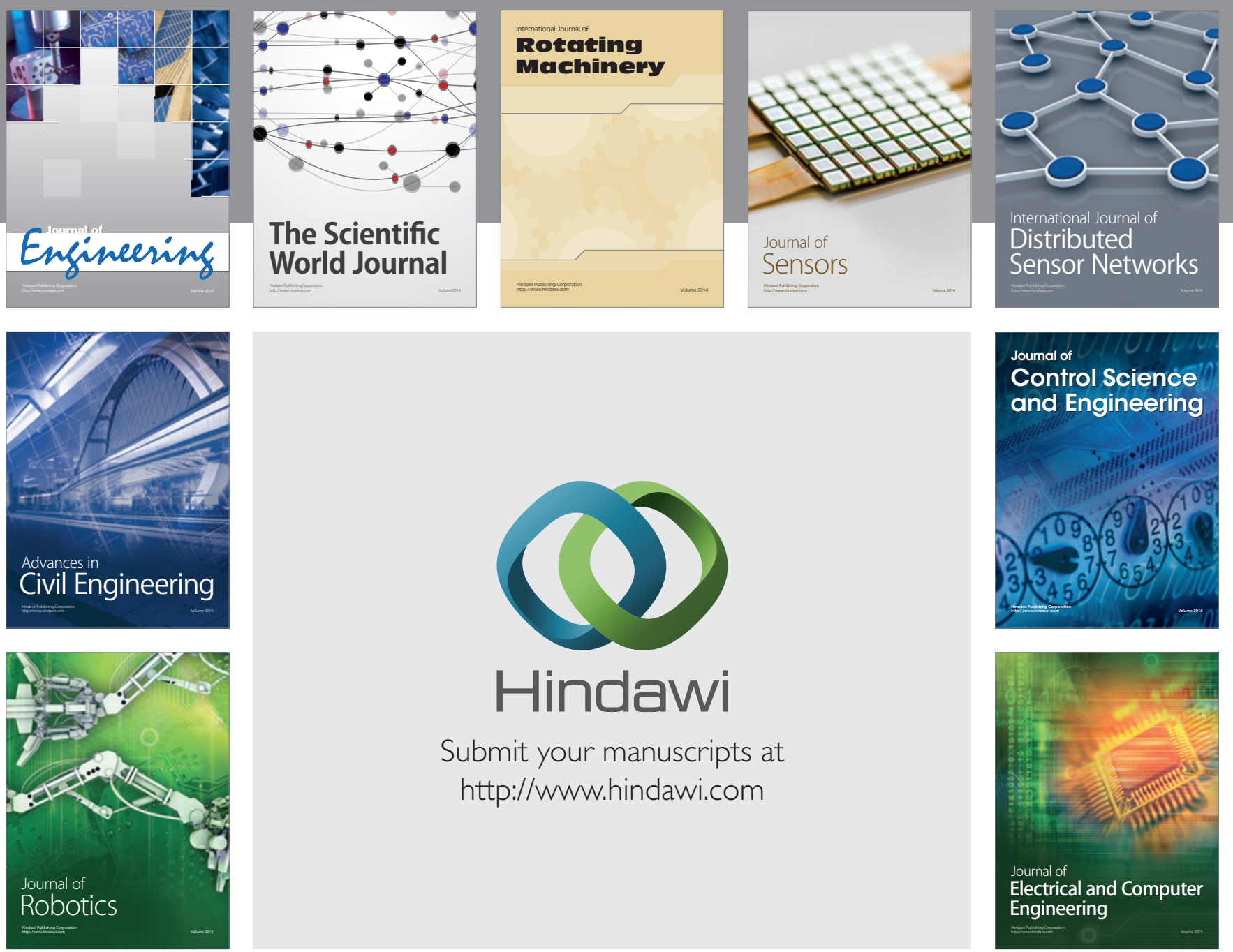

Submit your manuscripts at

http://www.hindawi.com
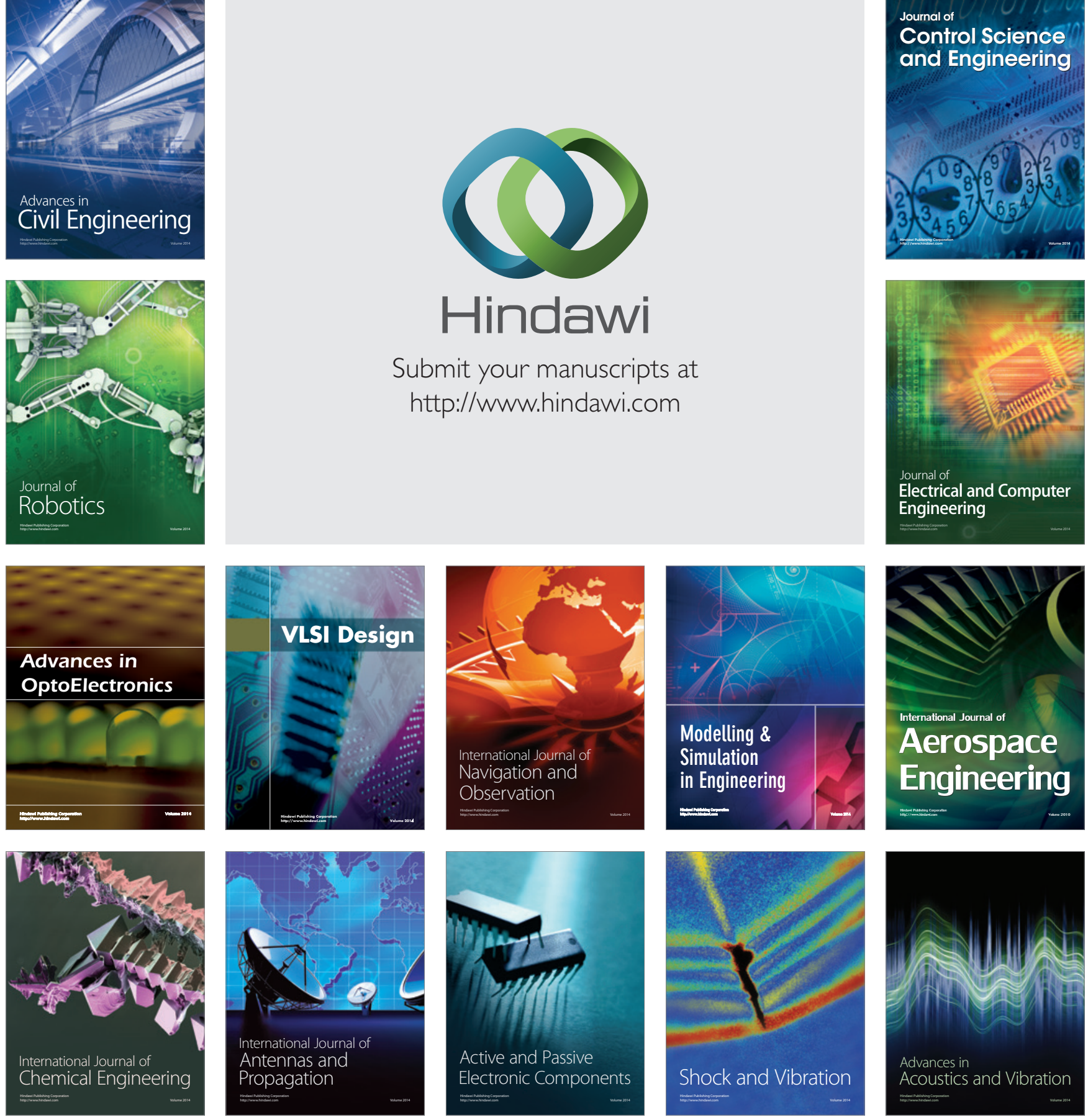